Research Article

\title{
Research on Systemic Risk of the Turkish Banking Industry Based on a Systemic Risk Measurement Framework of the Fractional Brownian Motion
}

\author{
Hong Fan (iD, Lingli Feng, and Ruoyu Zhou \\ Glorious Sun School of Business and Management, Donghua University, Shanghai 200051, China \\ Correspondence should be addressed to Hong Fan; hongfan@dhu.edu.cn
}

Received 6 September 2021; Accepted 15 October 2021; Published 31 October 2021

Academic Editor: Baogui Xin

Copyright (c) 2021 Hong Fan et al. This is an open access article distributed under the Creative Commons Attribution License, which permits unrestricted use, distribution, and reproduction in any medium, provided the original work is properly cited.

\begin{abstract}
Since the 2008 financial crisis, it is an important issue to assess the systemic risk of banks, but there is a lack of research on the assessment of the systemic risk of Turkey's financial system. In addition, geometric Brownian motion is used in most of the assessment frameworks of systemic risk under the normal financial market state, while the Turkish financial market has the situation of spike and thick tail. Therefore, this paper proposes a fractional Brownian motion measurement framework of systemic risk to study the systemic risk of the Turkish financial system. Firstly, this paper uses the data of 11 Turkish listed banks from 2014 to 2019 to conduct a normality test and demonstrate that its market has the characteristics of a fractal market; that is, there is a spike and thick tail distribution phenomenon in the stock price trend. Then, this paper proposes a fractional Brownian motion systemic risk measurement framework (fBSM). Based on the proposed theoretical framework and the actual data of Turkish listed banks from 2014 to 2019, a dynamically evolving Turkish banking network system is constructed to measure the systemic risk in the Turkish banking system. The research results find that the systemic risk is the highest in 2017, which then improved and gradually recovered. In addition, when analyzing the sensitivity of the Hurst index, it shows that with the increase in Hurst index, the Hurst index elasticity of Turkish banks' asset value increases gradually and the asset value also increases continuously. Hence, the Hurst index has a greater impact on asset value. Therefore, the measurement framework of systemic risk based on the fBSM can better monitor the systemic risk than the traditional geometric Brownian motion in the Turkish banking system.
\end{abstract}

\section{Introduction}

Due to the global financial crisis that broke out in 2008, countries around the world have experienced bank failures. The financial crisis led to the collapse of many large banks in the United States. Lehman Brothers, the fourth-largest investment bank in the United States with a history of 158 years, declared bankruptcy, which became a landmark event of the financial crisis. On the same day, Merrill Lynch, the thirdlargest investment bank, was acquired by Bank of America. Six days later, Goldman Sachs and Morgan Stanley, the two largest investment banks in the United States, announced their conversion to bank holding companies. Others include Bear Stearns, Fannie Mae and Freddie Mac, and AIG, which are facing financial crisis or being taken over or acquired by the government or declared bankrupt. Some were once the top five investment banks in the United States, the world's largest insurance company, and large government-funded institutions. At the same time, the financial crisis in the United States quickly spread to all countries in the world. Many countries have been impacted by the crisis, including bank financial crisis, bank run, bankruptcy, currency devaluation, a sharp decline of the stock market, sharp contraction of credit, a bond default, and so on. Affected by the crisis, global economic growth has stagnated, and asset prices have shrunk dramatically. The dependence on international capital makes Turkey's economy vulnerable to economic fluctuations in Europe and the United States. In the global financial crisis triggered by the US subprime mortgage crisis, Turkey's financial market has been greatly impacted, such as the contraction of the national economy, the rising unemployment rate, and the double deficit of the balance of payments. 
Therefore, the study of systemic risk has become very important.

As a major import-dependent emerging market country, Turkey's banking assets have been growing steadily over the past decade. However, over time, growth in Turkey became increasingly dependent on externally funded credit and demand stimulus. In addition, the original high inflation rate and President Erdogan's opposition to high-interest rates and the implementation of a low-interest rate policy have led to serious internal and external imbalances in Turkey's economic situation. Under the impact of various negative factors at home and abroad, Turkey's economy is relatively weak after 2013. According to the International Monetary Fund (IMF), Turkey's economy grew at an average annual rate of $3.66 \%$ from 2013 to 2017. Especially since 2016, the money supply of Turkey's central bank has been increasing, and the uncontrolled issuance of additional money has made more and more money circulating in the market. In addition, Turkey not only has high foreign debt and weak solvency but also has a high proportion of short-term foreign debt. These factors led to the acceleration of asset quality fission and the decline of the business capability of the Turkish banking industry [1]. So an in-depth analysis of the systemic risk of Turkey bank is of great significance.

The purpose of systemic risk measurement is to detect risks in time, so as to adopt macroprudential policies to deal with risks and prevent crises. At present, many scholars focused on the measurement of systemic risk. Based on VaR (value at risk), Adrian and Brunnermeier [2] propose to measure the systemic risk of the whole financial system using $\mathrm{CoVaR}$, that is, the conditional at risk value method. Bai and Shi [3] measure the systemic risk of 27 domestic listed financial institutions based on the CoVaR method, but the limitation of $\mathrm{CoVaR}$ is the risk of the whole financial system when each institution in the system is in crisis, and the method did not consider the relationship between institutions in the system. For the first time, Acharya [4] and others have used the marginal expected shortfall (MES) method to measure the contribution of individual financial institutions to the financial system, but they assume that the correlation between individual financial institutions and the market is constant. Based on the data of 14 listed banks in China, Wu [5] used MES (marginal expected loss) method to study the contribution of systemic risk of listed banks in China. Huang [6] proposed DIP (distress insurance premium) to calculate measurement system risk. Tarashev [7] applies the Shapley value concept in cooperative game theory to systemic risk analysis to measure the contribution of a single financial institution to systemic risk, that is, to measure the systemic importance of a financial institution. The above four methods are based on financial market data such as the stock market, but they all neglect the interbank relationship among banks in the system.

In recent years, more and more scholars combined the accounting information of banks with stock market data to study the systemic risk of the financial system. The BSM model proposed by Black and Scholes [8] and Merton [9] can be used to estimate the asset value of banks. Lehar [10], for the first time, uses the CCA (contingent claims analysis) method based on the BSM model to conduct systemic risk research by using market data and corporate financial information of banks in developed countries in Europe. Sun and Wei [11] applied the CCA method to the measurement of macrofinancial risks and banking sector risks in China, and the results were in good agreement with the development of China's economy and finance. Although these kinds of literature use comprehensive data, they also fail to take into account the contagious risks posed by the relationships between institutions within the system.

The relationship among financial institutions means that interbank lending forms an interbank lending network, which also provides a channel for interbank transmission. For the first time, Allen and Gale [12] considered the interbank lending network in the research of systemic risk and considered that the complete market structure is more stable than the incomplete market structure in the face of external shock. When analyzing the risk of bank default caused by infection, Eisenberg and Noe [13] found that there were clearing payment vectors among the interbank lending networks and proposed the Eisenberg-Noe framework. Upper and Worms [14] used the maximum entropy method to estimate the interbank loan and deposit distribution of a single bank and analyzed the possibility of the systemic risk infection in the German banking industry. In addition to the above literature, many researchers have also theoretically studied the effect of network structure on contagion risk based on the maximum entropy method [15-22]. Although great progress has been made in the research on the contagion risk in the interbank network system, the existing research has some limitations. Most studies are based on static network structures (fixed bank lending matrixes) and static banking systems (fixed bank balance sheets). However, the reality of interbank network systems is highly complex dynamics.

At present, a small number of dynamic systemic risk studies use the classic Black-Scholes pricing model [23-25]. However, there is no research on the dynamic evolution of systemic risk in the Turkish banking system. The classic Black-Scholes pricing model assumes that the underlying assets follow the unbiased geometric Brown motion, which means that the underlying assets are assumed to follow the normal distribution. However, through the normality test of Turkey's bank stock market, we find that the fluctuation of its stock price has an obvious phenomenon of "sharp peak and thick tail," which is characterized by long-term dependence and self-similarity. It is not subject to unbiased random walk, that is, the future price movement of a stock is related not only to the current price but also to the price over a considerable period in the past. This means that if the classical Black-Scholes pricing model based on geometric Brownian motion is used to study Turkey's systemic risk, there will be a certain deviation from the phenomenon in the real capital market, which is inconsistent with reality. The fractional Brown motion (fBSM) is a Gauss process with the characteristics of long dependence, self-similarity, and thick tail distribution, which is the same as the characteristics of financial assets in the real capital market. These characteristics make the fractional Brown motion model an important tool in the research of financial practice, and it is similar to the distribution of the stock market in Turkey. Li [26] analyzed the market data of the China securities market 100 index, found that it has the characteristics of a divided market, and used the fractional 
Brown motion model to evaluate its enterprise value. Cheng [27] used three different methods, namely, the classic Black-Scholes pricing model, Monte Carlo simulation option pricing method, and fractional Brown motion, to conduct an empirical analysis on the price of 50ETF options in the Shanghai Stock Exchange. It found that the fractional Brown motion can accurately simulate the price of options in the Shanghai Stock Exchange compared with the other two models. Therefore, this paper will combine the option pricing model based on the fractional Brown motion to conduct to measure the dynamic evolutional systemic risk of Turkey.

In this paper, we will use the idea of calculating the systemic risk proposed by Fan [23-25] and adopt the CCA method based on the fractional Black-Scholes option pricing model, the Eisenberg-Noe framework, and the matrix method under the maximum entropy to propose the dynamic evolution theoretical framework of the systemic risk and then based on this theoretical framework, the market data, and accounting information of the Banks of Turkey to analyze the systemic risk of Turkey.

Since the information of assets and liabilities is not collected every day, this paper uses the fractional Brown motion model to estimate the asset value of a bank: before using the fractional Brown motion model to estimate the asset value of a bank, it needs to use the R/S analysis method to estimate the value of the Hurst index $\mathrm{H}$; then, the $\mathrm{H}$ value of Hurst index obtained by R/S analysis is brought into the fractional Brown motion model to estimate the asset value of the bank. Assuming that the liabilities grow at the risk-free interest rate, the value of the liabilities of the bank can be calculated by collecting the risk-free interest rate. Since the specific interbank lending data is not publicly available, it is necessary to estimate the interbank lending matrix within the banking system using the matrix method based on the principle of maximum entropy. Among them, the principle of maximum entropy assumes that the network is fully connected. The combination of the fractional Black-Scholes option pricing model (hereinafter referred to as the fBSM model), the matrix method, and the maximum entropy principle can well solve the dynamic evolution estimation problem of banks' assets and liabilities and the internal lending assets and liabilities and provide an important data basis for the judgment of systemic risk.

This paper is organized as follows: Section 2 proposes a dynamic evolution model of bank systemic risk assessment based on fractional Brownian motion. In the theoretical model, Section 2.1 first introduces the estimation method of the matrix; Section 2.2 proposes the estimation method of asset market value based on fractional Brownian motion; and Section 2.3 discusses the measurement method of systemic risk, including basic default and contagious default. Section 3 describes the data used in this study and the empirical results of the Turkish banking industry. Section 4 summarizes this paper.

\section{Materials and Methods}

This paper first establishes the dynamic evolution theoretical framework of the Turkish banking network system based on the fractional Brown motion, as shown in Figure 1.
We assume that there are $M$ banks in the system; each bank has a dynamically evolved bank balance sheet structure as shown in Figure 1(a). Each bank's assets include interbank lending assets $a_{i}(t)$ and external assets $V_{i}(t)$. Each bank's liabilities include interbank loan liabilities $l_{i}(t)$ and external liabilities $D_{i}(t)$. Each bank's assets minus liabilities is the owner's equity $E_{i}(t)$. Bank asset update is determined by the fBSM model. Before using the fBSM model, it is necessary to determine whether the stock market conforms to the characteristics of fBSM, that is, stock prices do not follow the normal distribution but follow the spike-thick-tailed distribution. This makes it necessary to test the normality of stock prices and calculate the Hurst index (Figure 1(b)). There is interbank market risk exposure in the system, as shown in Figure 1(c) The payment matrix of the interbank market risk exposure can be described as equation (1), which shows the interbank loan assets $a_{i}(t)$ and the interbank loan liabilities $l_{i}(t)$ ). At time step $t$, the dynamic evolution of bank assets and liabilities leads to the dynamic loss of bank external assets (see the dashed boxes $\operatorname{Loss}_{i}(t)$ and $\operatorname{Loss}_{j}(t)$ in Figure 1(a)). The interbank loan assets $a_{i}(t)$ and interbank loan liabilities $l_{i}(t)$ are dynamic, so the interbank market risk exposure is also dynamically evolving. As shown in Figure 1(d), the dynamic interbank market network structure $X(t)$ evolved from time step $t=0$ to time step $t=365$. Each node represents a bank, and each line indicates a loan relationship. The line is bidirectional, and the arrow points to the borrowing bank. The line thickness and the node size indicate the proportion of loans. The larger the node, the greater the weight of bank loan assets in the total loan assets of the whole bank network. At each time step, we use the clearing payment vector to conduct asset and liability liquidation on the banking system to calculate the systemic risk of the banking system at each time step.

2.1. Estimation of the Interbank Lending Matrix. A lending relationship exists among the banking system, but due to the difficulty in obtaining specific lending data between one bank and other banks, it is necessary to estimate the lending matrix data using certain algorithms. In the literature [24,25], the maximum entropy principle and matrix method are used to estimate the interbank network of China. Similarly, the matrix method and maximum entropy principle algorithm are also used to estimate the interbank network of Turkey.

The banking network is constructed with $M$ banks. Based on the relationship between their lending assets and their lending liabilities, an $M \times M$ lending matrix can be formed, as shown in equation (1), where $x_{i j}$ represents the amount of bank $i$ lending to bank $j$, which is an asset to bank $i$ and a liability to bank $j . a_{i}$ represents the total amount of interbank lending assets lent by bank $i, l_{j}$ represents the total amount of interbank lending liabilities borrowed by bank $j$ to other banks, and $a_{i}$ and $l_{j}$ must satisfy equations (2) and (3), respectively, and simultaneously in equation (4), $X^{\Sigma}$ represents the total funds in the lending market. Since when collecting the data on borrowing and lending assets, only the total amount of borrowing assets and liabilities of each bank can be collected, and detailed data on the borrowing and 


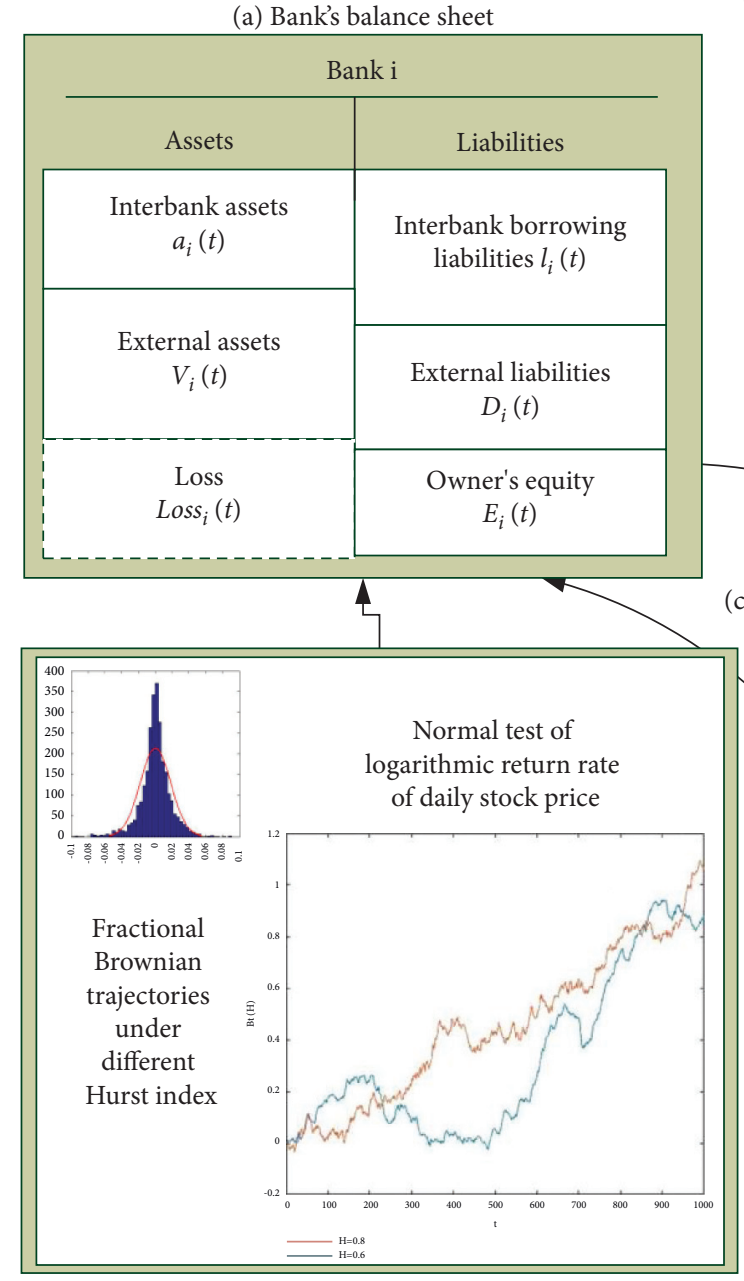

(b) Hurst index analysis

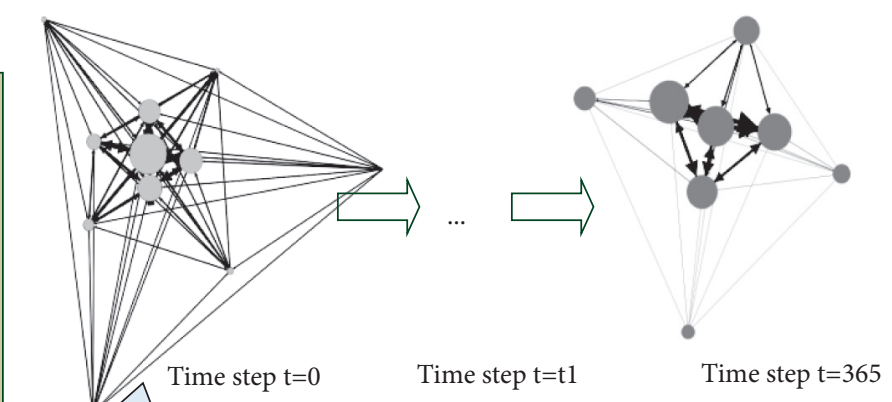

(d) Dynamic network structure X (t) of interbank market

(c) Interbank market
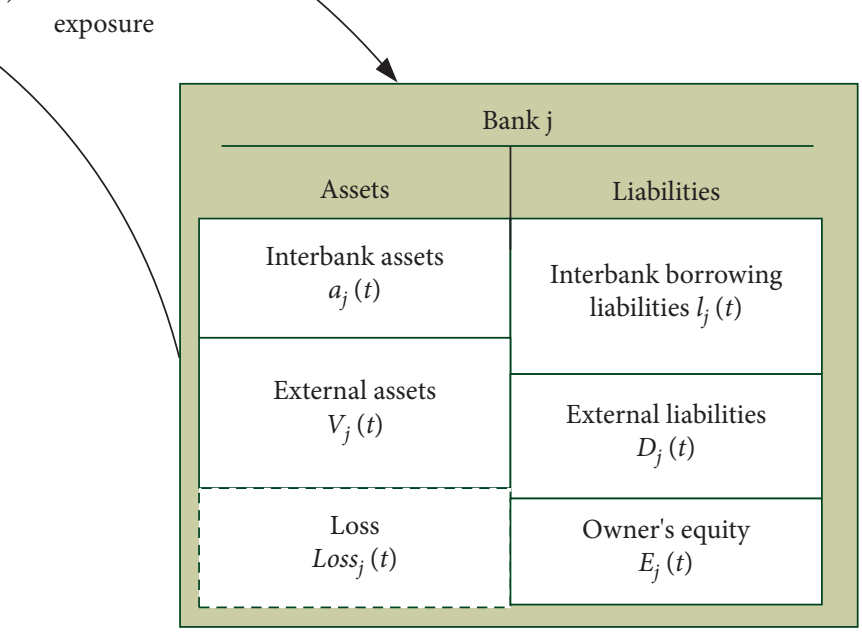

(a) Bank's balance sheet

FIGURE 1: A dynamically evolving banking network model in Turkey: (a) bank's balance sheet, (b) Hurst index analysis, (c) interbank market exposure, and $(\mathrm{d})$ dynamic network structure $X(t)$ of the interbank market.

lending among each bank cannot be collected, it is necessary to process the original data and use the maximum entropy to estimate the lending matrix $X$.

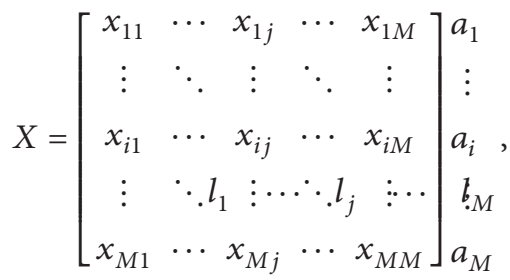

$$
\begin{aligned}
& a_{i}=\sum_{j=1}^{M} x_{i j}, \\
& l_{j}=\sum_{i=1}^{M} x_{i j}, \\
& \sum_{i} a_{i}=\sum_{j} l_{j}=X^{\Sigma} .
\end{aligned}
$$

2.1.1. Maximum Entropy Principle. First, a bank's lending and borrowing data are standardized, that is, new standardized data $a_{i}^{\prime}$ and $l_{j}^{\prime}$ are obtained as follows:

$$
\begin{aligned}
& a_{i}^{\prime}=\frac{a_{i}}{\sum_{i} a_{i}}, \\
& l_{j}^{\prime}=\frac{l_{j}}{\sum_{j} l_{j}} .
\end{aligned}
$$

Then the standardized lending amount $X^{\prime}$ is calculated according to equation (6). Since there is no lending by the bank itself, $x_{i j}^{\prime}$ is 0 on the diagonal of the matrix. This matrix $X^{\prime}$ is a priori, standardized matrix that reflects the relative importance of banks in the interbank lending market.

$$
X^{\prime}= \begin{cases}0, & i=j, \\ a_{i}^{\prime} * l_{j}^{\prime}, & i \neq j .\end{cases}
$$


To solve the problem that $X$ I does not satisfy equations (2) and (3), the following equation is proposed [14, 15, 28]:

$$
\begin{aligned}
& \min \sum_{i=1}^{M} \sum_{j=1}^{M} x_{i j} \ln \left(\frac{x_{i j}}{x_{i j}^{\prime}}\right), \\
& \text { s.t. }\left\{\begin{array}{l}
\sum_{j=1}^{M} x_{i j}=a_{i}, \\
\sum_{i=1}^{M} x_{i j}=l_{i}, \\
x_{i j} \geq 0 .
\end{array}\right.
\end{aligned}
$$

2.2. Dynamic Evolutionary Estimation Model of Asset Value. A bank's asset value $V_{i}(t)$ is not visible daily. However, the value of assets and liabilities at the end of the year can be obtained through the annual report, and the equity value of the bank can be calculated by the daily stock price. In this paper, time $t$ is measured in days. Next, this paper presents a method to estimate the daily asset value (the time evolution of the asset value) based on the data of the stock market.

2.2.1. Fractional Brownian Motion. As can be seen from the definition of the fractional Brownian motion [29], one of its very important properties is self-similarity. In addition, the fractional Brownian motion is a Gaussian process. It no longer has Markovian characteristics but has long-term similarity, self-similarity, and "spike and thick tail" characteristics. These characteristics make the fractional Brownian motion a powerful tool in recent years in mathematical finance research, which can highly fit the actual fluctuation trajectory of assets. The fBSM model assumes that the underlying assets price follows a biased walk-through process, so the option price also belongs to a biased random process. The underlying asset price follows a biased fractional Brownian motion, that is,

$$
\mathrm{d} V_{i} \mathrm{~d} t=\mu V_{i} \mathrm{~d} t+\sigma V_{i} \mathrm{~d} B_{t}^{H},
$$

where $V_{i}$ is the underlying assets of bank $i, \mu$ is the drift rate of the underlying assets, $\sigma$ is the volatility of the underlying assets, and $B_{t}^{H}$ represents the fractional Brownian motion subject to the Hurst index of $H(H \in[1 / 2,1])[30]$, and

$$
\mathrm{d} B_{H}(t)=\varepsilon \sqrt{\mathrm{d} t^{2 H}}, \varepsilon \sim N(0,1) .
$$

In equation (9), when $H=1 / 2$, then the fractional Brownian motion changes to the standard Brownian motion.

Thus, the process of determining the equity value is similar to option pricing, in which the total assets of $V_{i}$ can be used as the asset price of the option, and the total liabilities of the bank (the debt maturity date is $T$ ) can be used as the option execution price. According to Lehar [10], this paper assumes that all bank debts are insured, so the debt will grow at a risk-free rate, that is,

$$
D_{i}(T)=D_{i}(0) e^{r t}=D_{i}(T) e^{-r *(T-t)},
$$

where $D_{i}(T)$ is equal to the discount value of the option exercise price $D_{i}(T)$. Then, the equity value of the enterprise can be expressed as follows:

$$
\begin{aligned}
E_{i}(t) & =V_{i}(t) N\left(d_{1 t}\right)-D_{i}(t) e^{-r T} N\left(d_{2 t}\right) \\
d_{1 t} & =\frac{\ln \left(V_{i}(t) / D_{i}(t)\right)+r(T-t)+1 / 2 \sigma^{2}\left(T^{2 H}-t^{2 H}\right)}{\sigma_{i} \sqrt{T^{2 H}-t^{2 H}}} \\
d_{2 t} & =d_{1 t}-\sigma_{i} \sqrt{T^{2 H}-t^{2 H}}
\end{aligned}
$$

where $T$ is the maturity and $T=365$.

Combining Ito's lemma to solve the fractional Brownian motion can get the calculation equation of asset value as follows:

$$
V_{i}(t)=V_{i}(0) \exp \left[\mu_{i}(T-t)+\sigma_{i}\left(B_{H}(T)-B_{H}(t)\right)-\frac{1}{2} \sigma_{i}^{2}\left(T^{2 H}-t^{2 H}\right)\right] .
$$

Because $B_{H}(t)$ is the fractional Brownian motion, it can be replaced by $\sqrt{T^{2 H}-t^{2 H}} Z$. In this paper, we firstly set any initial value of drift rate and volatility, denoted as $\mu_{i}(0)$ and $\sigma_{i}(0)$, and we set the initial value is 0 and then take the data of the listed bank's annual report of the previous year (assets at the end of the year) as the initial asset value of the year $V_{i}(0)$ and the owner's equity value of each day that can be expressed as $E_{i}(0), E_{i}(1), \ldots, E_{i}(T)$. According to equation (10), the liability can be expressed as $D_{i}(0), D_{i}(1), \ldots, D_{i}(T)$; then we can get the assets estimated value of each day as $\widehat{V}_{i}(1)$, $\widehat{V}_{i}(2), \ldots, \widehat{V}_{i}(T)$ according to equations (11)-(13). The maximum likelihood function proposed by Duan [31-33] is used to calculate the parameter of drift rate $\mu_{i}$ and volatility $\sigma_{i}$ as follows:

$$
\begin{aligned}
L\left(\mu_{i}, \sigma_{i} ; \widehat{V}_{i}(1), \widehat{V}_{i}(2), \ldots, \widehat{V}_{i}(T)\right) & =-\frac{T}{2} \ln \left(2 \pi \sigma_{i}^{2} h\right) \\
& -\frac{T}{2} \sum_{K=1}^{T} \frac{\left(F_{i}(k)-\left(\mu_{i}-\sigma_{i}^{2} / 2\right) h\right)^{2}}{\sigma_{i}^{2} h} \\
& -\sum_{K=1}^{T} \ln \widehat{V}_{i}(k),
\end{aligned}
$$

where $F_{i}(k)=\ln \left(\widehat{V}_{i}(t) / \widehat{V}_{i}(t-1)\right)$ and $h=1 / T$.

Finally, the drift rate $\widehat{\mu}_{i}$ and volatility $\widehat{\sigma}_{i}$ estimated by equation (15) are substituted into equation (14) to estimate the assets of bank $i$.

2.2.2. R/S Analysis Method. In the European option pricing model driven by the fractional Brownian motion, one of the important parameters is the Hurst index. In this paper, the method of rescaled range $(R / S)$ is used to estimate the Hurst index $H$. 
For a time series $\left\{Y_{t}, t=1,2,3, \ldots, n\right\}$, the mean value is defined as $\bar{Y}$, the standard deviation as $S_{Y}$, and the range as $R$, and the calculation equation of each parameter is as follows:

$$
\begin{aligned}
\overline{Y_{n}} & =\frac{1}{n} \sum_{t=1}^{n} Y_{t}, \\
R(n) & =\max _{1 \leq k \leq n} \sum_{i=1}^{k}\left(Y_{i}-\overline{Y_{n}}\right)-\min _{1 \leq k \leq n} \sum_{j=1}^{k}\left(Y_{j}-\overline{Y_{n}}\right), \\
S_{Y}(n) & =\left[\frac{1}{n} \sum_{i=1}^{n}\left(Y_{i}-\overline{Y_{n}}\right)^{2}\right]^{1 / 2} .
\end{aligned}
$$

Then, the statistic $R / S$ is as follows:

$$
Q_{n}=\frac{R(n)}{S_{Y}(n)} \text {. }
$$

It can be proved that [34]

$$
Q_{n}=(b * n)^{H}
$$

where $b$ is a constant and $H$ is the Hurst index. Since

$$
\ln \left[E\left(Q_{n}\right)\right]=A+H \ln n,
$$

where $A$ is a constant, taking $\ln n$ as the independent variable and $\ln Q_{n}$ as the dependent variable, the Hurst index $H$ can be obtained by least square regression.

2.3. Assets Liquidation. The existence of interbank lending in the banking system is the cause of contagion risk. According to the E-N framework proposed by Eisenberg and Noe [13], this paper carries out asset liquidation for the whole banking system and dynamically evolves the interbank network system by removing the default banks to update the network structure.

There are $M$ banks in the whole banking system. When $t \in[0, T]$, the network system can be expressed as $(X(t), e(t))$, where $X(t)$ is a $M \times M$ nominal interbank liabilities matrix (see $X(t)$ in Figure $1(\mathrm{c})$ ), and $e_{i}(t)$ represents the owner's equity of bank $i$ at time $t$, that is, the difference between the market value of assets and the market value of liabilities. When the equity is less than 0 , bank $i$ fails in a basic way; when it is greater than 0 , it is still impacted by the liquidity risk caused by the interbank market.

2.3.1. Basic Default. The condition for the occurrence of a basic default by bank $i$ is as follows:

$$
V_{i}(t)-D_{i}(t)<0 \text {. }
$$

According to Section 2.2, $V_{i}(t)$ is a random walk variable. If equation (20) is satisfied, then the default of bank $i$ is caused by the bank's mismanagement, which is independent of the interbank lending market, so we define the default as the basic default.
2.3.2. Contagious Default. The definition of contagious risk in this paper is as follows: assuming that bank $i$ suffers an external impact, resulting in the loss of its external assets, and the loss is greater than its owner's equity, bank $i$ is forced to liquidate, and its interbank loan cannot be fully repaid. At this time, it leads to the loss of the interbank loan of bank $j$. If the loss is greater than the owner's equity of bank $j$, bank $j$ will also go bankrupt; this forms the risk of contagion between banks. At this time, bank $j$ will also be forced to liquidate, which may also cause a new round of contagion and domino effect.

Let $l_{j}(t)=\sum_{i=1}^{M} x_{i, j}(t)$ denotes the total interbank liabilities of bank $j$ to all banks in the system. In addition, this paper considers a matrix $\prod(t) \in[0,1]^{M \times M}$, which is obtained by standardizing the debt matrix, that is described as follows:

$$
\Pi_{i j}(t)= \begin{cases}\frac{x_{i j}(t)}{l_{j}(t)}, & \text { if } l_{j}(t)>0, \\ 0, & \text { otherwise. }\end{cases}
$$

We define a clearing payment vector $p_{i}^{*}(t)$ as follows:

$$
p_{i}^{*}(t)= \begin{cases}l_{i}(t), & \sum_{j=1}^{M} \Pi_{i j}(t) p_{j}^{*}(t)+e_{i}(t) \geq l_{i}(t), \\ \sum_{j=1}^{M} \Pi_{i j}(t) p_{j}^{*}(t)+e_{i}(t), & 0 \leq \sum_{j=1}^{M} \Pi_{i j}(t) p_{j}^{*}(t)+e_{i}(t) \leq l_{i}(t), \\ 0, & \sum_{j=1}^{M} \Pi_{i j}(t) p_{j}^{*}(t)+e_{i}(t) \leq 0,\end{cases}
$$

where in the first case, bank $i$ is solvent, and in the latter two cases, bank $i$ is insolvent.

This paper uses the default algorithm established by Eisenberg and Noe [12] to find the clearing payment vector $p_{i}^{*}(t), i \in[1, M]$.

At this time, if the loss is too large and bank $i$ is insolvent, default and bankruptcy will occur. This situation is called default caused by the spread of contagious risk, that is, contagious bankruptcy, which is described by

$$
\left(\sum_{j=1}^{M} \Pi_{i j}(t) p_{j}^{*}(t)-l_{i}(t)\right)+e_{i}(t)<0,
$$

where $\sum_{j=1}^{M} \Pi_{i j}(t) p_{j}^{*}(t)$ is the interbank lending for bank $i$, $l_{i}(t)$ is the interbank liabilities of bank $i, e_{i}(t)=V_{i}(t)-$ $D_{i}(t)$ is the owner's equity of bank $i$ outside the interbank market, and $\sum_{j=1}^{M} \Pi_{i j}(t) p_{j}^{*}(t)-l_{i}(t)$ is the owner's equity of bank $i$ in the interbank market. If equation (23) is true, then the total owner's equity of bank $i$ is less than 0 and bank $i$ shows the contagion default.

2.4. Dynamic Evolution of Interbank Network. After calculating the clearing payment vector at time $t$, we need to remove the defaulted bank that is bankrupt to update the banking network structure at time $t+1$. 
It can be seen from the above that when bank $i$ defaults, bank $i$ can only pay part of its debts to other creditor banks. A payment ratio $\chi_{i}$ is defined as follows:

$$
\chi_{i}=\frac{\sum_{j=1}^{M} \Pi_{i j}(t) p_{j}^{*}(t)+e_{i}(t)}{l_{i}(t)} .
$$

From step $t+1$ to step $T$, the total assets and liabilities of bank $j$ will be updated as follows:

$$
\begin{aligned}
& D_{j}(t+1: T)=D_{j}(t)-\sum_{i=1}^{M} x_{i j}, \\
& V_{j}(t+1: T)=V_{j}(t)-\sum_{i=1}^{M}\left(1-\chi_{i}\right) x_{j i} .
\end{aligned}
$$

Then, because bank $i$ defaults, this paper sets $x_{i j}(t)=0$, and $x_{j i}(t)=0$ clears bank $i$ from the banking network system. In the real world, the interbank market may change every day. In this paper, due to the existence of default banks, the number of banks will decrease, resulting in changing the interbank network over time. Please note that if there is no defaulting bank in $T$, the network will not change as the total number of banks in $t$ and $t+1$ remain unchanged.

Then, we need to recalculate and update the debt matrix $X(t+1)$ according to the algorithm in Section 2.1. So the evolution of $a_{j}(t+1)$ and $l_{j}(t+1)$ are described as follows:

$$
\begin{aligned}
& a_{i}(t+1)=\sum_{i=1}^{M} x_{i j}(t+1), \\
& l_{j}(t+1)=\sum_{j=1}^{M} x_{i j}(t+1) .
\end{aligned}
$$

2.5. Calculation of Banking Systemic Risk. In the system, when the total assets of a bank are less than the total liabilities, the bank defaults (including basic default and contagion default), and the sum of default probabilities of all banks is called systemic risk. This paper defines the basic default when the total assets of bank $i$ are less than the total liabilities due to the loss of external assets. When the total assets of bank $j$ are less than the total liabilities, contagion default will occur due to the bankruptcy of bank $i$ and the inability to recover all interbank loans (the impact of interbank market risk exposure). In this paper, the basic default is represented by the basic failure probability $\mathrm{BD}(t)$; the contagious risk is represented by the contagious failure probability $\mathrm{CD}(t)$; and the systemic risk is represented by the system default probability $\mathrm{SR}(t) ; \mathrm{SR}(t)=\mathrm{BD}(t)+\mathrm{CD}(t)$.

$$
\begin{aligned}
\mathrm{BD}(t) & =\frac{\sum_{i=1}^{M} B \operatorname{Tag}_{i}(t)}{M}, \\
\mathrm{CD}(t) & =\frac{\sum_{i=1}^{M} C \operatorname{Tag}_{i}(t)}{M}, \\
\mathrm{SR}(t) & =\frac{\sum_{i=1}^{M} B \operatorname{Tag}_{i}(t)+\sum_{i=1}^{M} C \operatorname{Tag}_{i}(t)}{M},
\end{aligned}
$$

where Tag is a dummy variable and Tag $=\left\{\begin{array}{l}0, \text { the bank is healthy } \\ 1, \text { the bank defaults }\end{array}\right.$. The detailed explanation is as follows: the dynamic evolution process of banks is a relatively volatile state. In order to better estimate the systemic risk of the Turkish banking industry, we conducted a Monte Carlo simulation. In each simulation experiment, the failed bank will change. Therefore, we set the following: in 1,000 simulation experiments, when bank $i$ defaults more than 900 times, it is considered that the bank is in the default state and $\operatorname{Tag}_{i}=1$. When the number of defaults of bank $i$ is less than 900 , it is considered that the bank is healthy and $\operatorname{Tag}_{i}=0$. $B \mathrm{Tag}_{i}=1$ represents the default state caused by basic default (equation (20) holds), and $C \mathrm{Tag}_{i}=1$ represents the default state caused by contagious default (equation (23) holds).

\section{Empirical Research}

3.1. Data. This paper mainly studies the financial risk in Turkey, whose financial sector has been dominated by banks and accounts for the highest proportion of financial enterprises listed on the Istanbul Stock Exchange (ISE). Therefore, it can be concluded that the systemic financial risk in Turkey is mainly related to the banking industry [35]. This paper takes 11 local banks listed on the Istanbul Stock Exchange (ISE) in Turkey as a sample, obtains the annual financial statements data of 11 banks from the BvD ORBIS Bank Focus Global Bank and Financial Institution Analysis Library, obtains the stock prices and annual interest rates of 11 banks from the Yahoo Finance and Finance official website, and estimates their equity values. And the risk-free interest rate of Turkey's 10 year Treasury bonds was obtained from the International Monetary Fund (IMF) website (https://data.imf. org/regular.aspx?key=61545855). The total assets of the Turkish banking industry reached 4.5 trillion lira [36] in late 2019 , while the total assets of the 11 listed banks collected in 2019 were 3.72 trillion lira, accounting for $72.7 \%$. The 11 banks are AKBNK, ALBRK, GARAN, SAHOL, HALKB, SKBNK, ISCTR, VAKBN, YKBNK, TSKB, and DENIZ.

3.2. Empirical Analysis Results. Based on the data and models collected above, the assets and liabilities of each bank in Turkey's banking network structure and the evolution of the interbank network structure are estimated.

\subsubsection{Dynamic Evolution and Analysis of Turkish Banking} System Network. Figure 2 shows the evolutional banking network structure from 2014 to 2019 drawn based on the maximum entropy estimation, where each node represents a bank, each line represents the existence of borrowing and lending relationships, and the arrow points to the borrowing bank. The weight of the loan is reflected in the size of the node and the thickness of the line in the graph. The larger the node and the thicker the line, the greater the weight of the bank's loan assets in the total loan assets in the entire banking network.

This paper takes the network topology structure of Figure 2 in 2014 as an example. From Figure 2, it can be 


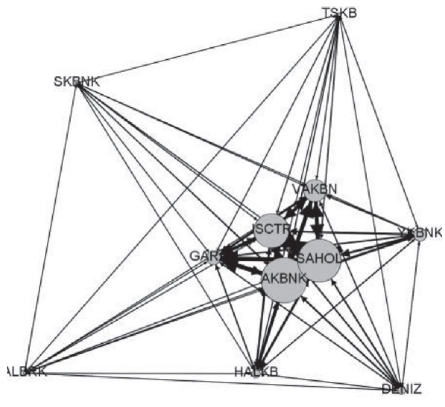

(2014)

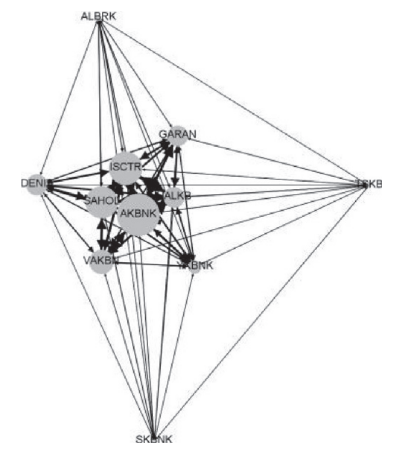

(2017)

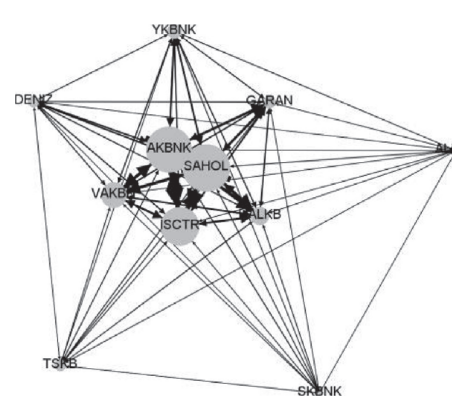

(2015)

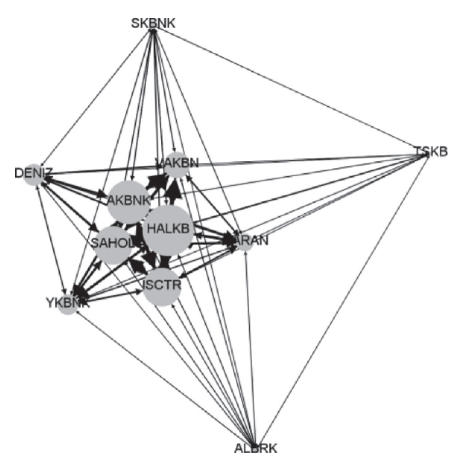

(2018)

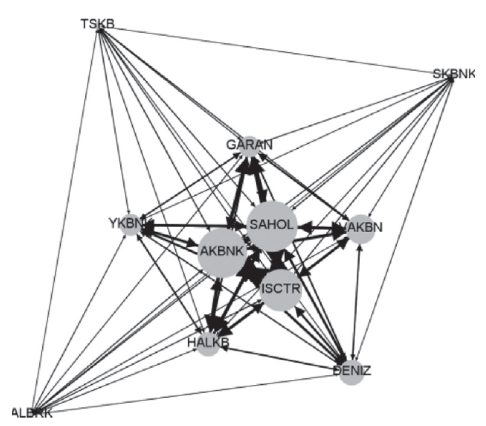

(2016)

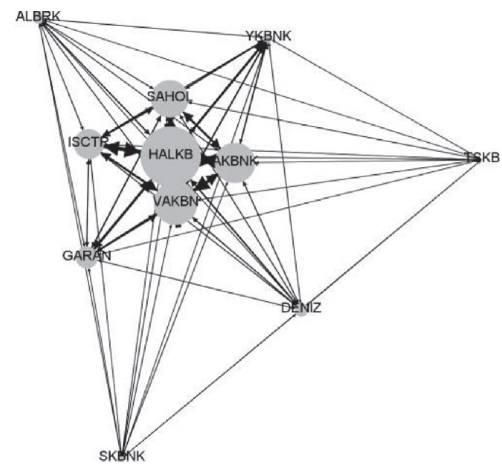

(2019)

Figure 2: The evolutional banking network structure from 2014 to 2019; the figure is drawn based on the maximum entropy estimation, where each node represents a bank, each line represents the existence of borrowing and lending relationships, and the arrow points to the borrowing bank. The weight of the loan is reflected in the size of the node and the thickness of the line in the graph. The larger the node, the greater the weight of the bank's loan assets in the total loan assets in the entire banking network.

found that AKBNK has the largest borrowing and lending ratio in the whole financial system, which is $23.676 \%$, followed by SAHOL bank that is $22.606 \%$. Taking AKBNK as an example, we can see that AKBNK focuses on the lending of ISCTR, SAHOL, VAKBN, GARAN, and other banks, while the lending ratio with other banks is lower. Figure 2 depicts the initial network structure of these 11 banks from 2014 to 2019 . Over time, the network structure will change, that is, the number of nodes, size, number, and thickness of connections in the diagram will change.

In the last few years, it can be seen that in the entire banking network, AKBNK Bank, SAHOL Bank, and ISCTR Bank have always been dominant, which also corresponds to the fact that the Turkish banking industry is one of the 10 strongest banks in Turkey. While ALBRK banks' influence decreases over time; on the contrary, HALKB banks and GARAN banks gradually occupy a place in the entire banking network, among which HALKB banks are more obvious.

3.2.2. Hurst Index Analysis of the Interbank Market in Turkey. To estimate the assets of banks in the banking system of fBSM model based on fractional Brown motion, we need to study the law of changes in the stock price of banks in Turkey to determine whether they are subject to normal distribution.
As the yield of the stock price is stable and ergodic, its statistical characteristics are often more useful than the original stock price. Therefore, when analyzing the data, the first step is to take the logarithm yield of the collected data, that is.

$$
Y_{t}=\ln \left(\frac{P_{t}}{P_{t-1}}\right),
$$

where $Y_{t}$ is the log yield at $t$ and $P_{t}$ is the closing price at $t$. Then, the logarithm yield of the stock price is tested for normality. Taking the share prices of 3 banks ALBRK/ ISCTR/HALKB in 2017 as an example, a histogram of the logarithmic yield of their stock prices is drawn, as shown in Figure 3:

From Figure 3, it can be seen that the histogram distribution is obviously not normal. To more accurately verify whether it obeys the normal distribution, the normality test is carried out by calculating the statistics of its series.

$$
\begin{aligned}
\delta & =\sqrt{\frac{1}{m-1} * \sum_{k=1}^{m}\left(Y_{k}-\bar{Y}\right),} \\
\mathrm{sk} & =\frac{1}{m} \sum_{k=1}^{m}\left(\frac{Y_{k}-\bar{Y}}{\delta}\right)^{3}
\end{aligned}
$$



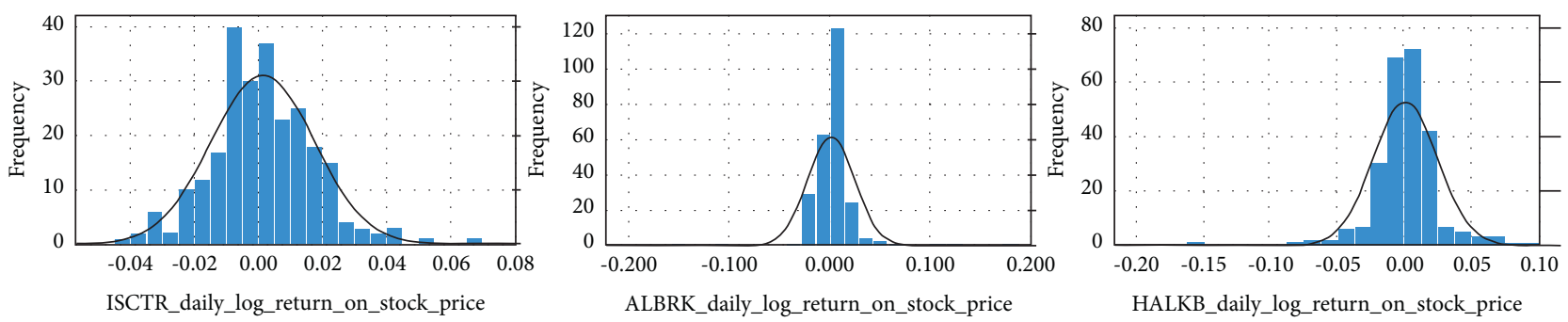

FIgURE 3: The logarithmic histogram of stock prices of ALBRK/ISCTR/HALKB. The $y$-axis is the frequency, and the $x$-axis is the logarithmic return of the daily stock price.

$$
K=\frac{1}{m} \sum_{k=1}^{m}\left(\frac{Y_{k}-\bar{Y}}{\delta}\right)^{4},
$$

where $m$ is the number of samples, $\bar{Y}$ is the mean of the sample sequence, $\delta$ is the standard deviation of the sample sequence (see equation (28)), and $s k$ is a measure of whether the distribution of the sample sequence is symmetrical or not, called skewness estimate (see equation (31)). When $s k=0$, the distribution of the tested sample sequence is symmetrical. When $s k>0$, the sample sequence has a right thick tail, that is, a longer right tail. When $s k<0$, the sample sequence has a left thick tail, that is, along the left tail. $K$ is a measure of how convex the distribution of the sample sequence is, also known as a kurtosis estimate, as shown in equation (32). To test the convexity of the sample sequence, the $K$ values obtained are compared with a fixed $K$ value of 3 in the normal distribution. When $K>3$, the distribution of sample series has a spike feature, that is, the degree of convexity is higher than that of normal distribution, whereas when $K<3$, the distribution of sample series is considered flat, and the degree of convexity is lower than that of normal distribution. And the statistics of ALBRK/ISCTR/ HALKB stock price logarithmic return are shown in Table 1.

It can also be obtained from Table 1 that the skewness of ALBRK's daily closing price to the logarithm yield in 2017 is 1.570 , and the kurtosis is 25.650 , which indicates that it has obvious peak characteristics. The $\mathrm{K}-\mathrm{S}$ nonparametric test on it also proves that its log yield series refuses the original assumption, so it does not conform to the normal distribution. The results are similar to those in Figure 3 through the normal test on the log yield of the daily stock closing price of 11 banks in Turkey. From Figure 3 and Table 1, it can be seen that there is a sharp peak and fat tail in the stock price trend of the banks. The normal test results reject the assumption that the logarithm yield of the stock price of the banks of Turkey follows a normal distribution, indicating that the stock price trend of the banks in the Turkey stock market does not conform to the geometric Brown motion assumption under the pricing of classic B-S options. Therefore, if the BSM model based on the geometric Brownian motion theory is used to estimate the option price of these 11 banks in Turkey, there will be a certain deviation, so it is more reasonable to use the $\mathrm{fBSM}$ model based on the fractional Brownian motion theory with scale characteristics to evaluate the asset value.

Table 2 is the Hurst index value calculated by the R/S analysis method of the logarithmic return rate of the stock prices of 11 banks in the past 6 years.
From Table 2, it can be seen that the Hurst index $\mathrm{H}$ of the daily closing price logarithm yield of the 11 banks in the past 6 years is greater than 0.5 , so it can be seen that these sequences do not satisfy the unbiased random walk process but a biased (and right-hand biased) random process with longterm memory and persistence, that is, the future trend of change is likely to be consistent with the past trend. Therefore, it is more reasonable to adopt the fractional Brown motion for the estimation of the asset value of banks.

3.2.3. Systemic Risk Analysis. After obtaining the evolution of assets and liabilities of each bank in the banking system and the evolution of the interbank network, the systemic risk of the banking system can be calculated. This paper estimates the theoretical default probability of the banking system in Turkey for 6 years from 2014-2019 as shown in Figure 4. Considering that the maximum entropy estimation produces a complete network, while the actual financial network market in Turkey is not a fully connected network, thus reducing the risk measure of the system.

Figure 4 shows the default probability of the systemic risk in Turkey's banking industry from 2014 to 2019 (see Table 3 for specific values). Table 3 shows the bank state and systemic risk in Turkey from 2014 to 2019. When the value in Table 3 is 1 , the bank is in default (including basic default and contagion default); on the contrary, the bank is healthy. The last row indicates Turkey's systemic risk for 2014-2019 years, and the last column shows the category of these banks (state-owned or private banks). In Figure 4, the systemic risk faced by the entire banking system in 2016-2018 fluctuated around $0.27-0.37$, and the system stability was relatively poor, which may be due to the gradual decline in the profitability of the banking industry caused by the continuous depreciation of lira and the financial crisis in Turkey around 2017, while the systemic risk in 2019 was lower than that in previous years; it is believed that after the financial crisis, its banking system has improved.

In addition, Figure 4 also shows several banks that contributed to the systemic risk in Turkey between 2014 and 2019. From Figure 4 and Table 3, we can obtain the following:

(1) The default probability of AKBNK Bank, ALBRK Bank, SAHOL Bank, DENIZ Bank, and ISCTR Bank is always 0 , regardless of whether there is a financial crisis or not, (not shown in Figure 4), indicating 
TABLE 1: Logarithmic return statistic value.

\begin{tabular}{|c|c|c|c|c|c|}
\hline Bank name & $m$ & Mean value & Standard deviation & Skewness & Kurtosis \\
\hline ALBRK's 2017 daily closing price log yield & 252 & 0.001174 & 0.0233461 & 1.57 & 25.65 \\
\hline ISCTR's 2017 daily closing price log yield & 252 & 0.001367 & 0.0162068 & 0.356 & 1.095 \\
\hline HALKB's 2017 daily closing price log yield & 252 & 0.000625 & 0.0239999 & -0.808 & 8.276 \\
\hline
\end{tabular}

TABle 2: Hurst index of Turkish banks.

\begin{tabular}{|c|c|c|c|c|c|c|}
\hline Bank name & 2014 & 2015 & 2016 & 2017 & 2018 & 2019 \\
\hline AKBNK & 0.652769 & 0.656147 & 0.586048 & 0.58668 & 0.647368 & 0.668232 \\
\hline ALBRK & 0.629457 & 0.587927 & 0.63844 & 0.596201 & 0.600489 & 0.659161 \\
\hline GARAN & 0.652298 & 0.632535 & 0.642009 & 0.55874 & 0.60102 & 0.681015 \\
\hline SAHOL & 0.600595 & 0.670273 & 0.666381 & 0.569587 & 0.609148 & 0.687937 \\
\hline HALKB & 0.676798 & 0.652517 & 0.640908 & 0.622126 & 0.613306 & 0.702969 \\
\hline SKBNK & 0.676455 & 0.650333 & 0.677969 & 0.613078 & 0.626658 & 0.682499 \\
\hline ISCTR & 0.64333 & 0.622357 & 0.601151 & 0.598708 & 0.635926 & 0.668748 \\
\hline VAKBN & 0.666231 & 0.664583 & 0.604965 & 0.589275 & 0.618239 & 0.69186 \\
\hline YKBNK & 0.692973 & 0.625026 & 0.669931 & 0.640426 & 0.773327 & 0.69113 \\
\hline TSKB & 0.548016 & 0.644964 & 0.671721 & 0.655892 & 0.584476 & 0.663363 \\
\hline DENIZ & 0.602083 & 0.613773 & 0.598382 & 0.618572 & 0.71212 & 0.597471 \\
\hline
\end{tabular}

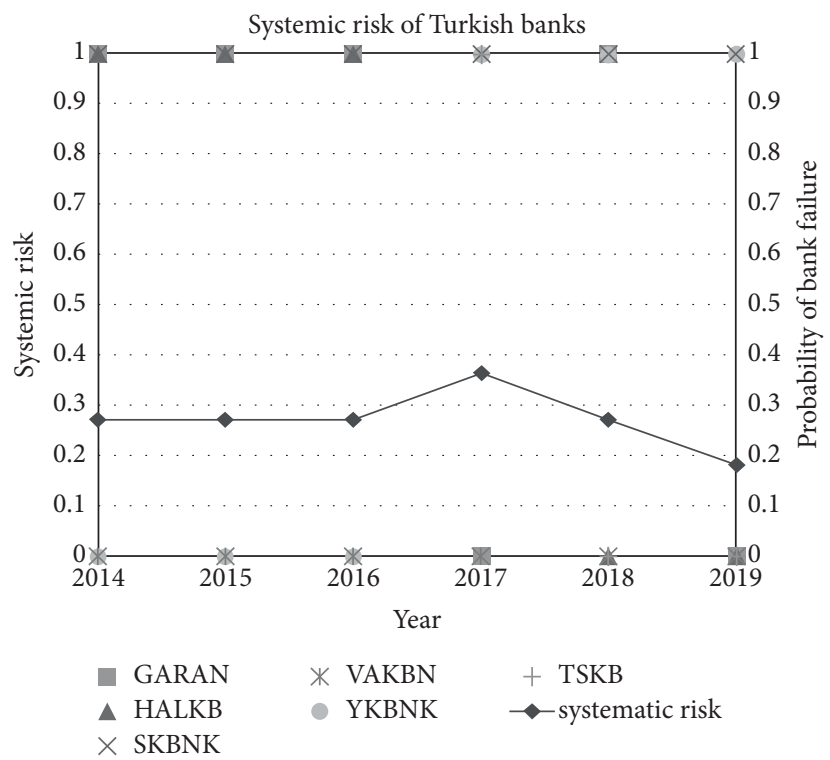

FIgURE 4: Systemic risks in Turkey in 2014-2019.

TABle 3: Bank state and systemic risk in Turkey.

\begin{tabular}{|c|c|c|c|c|c|c|c|}
\hline Bank name & 2014 & 2015 & 2016 & 2017 & 2018 & 2019 & Category \\
\hline AKBNK & 0 & 0 & 0 & 0 & 0 & 0 & Privately owned bank \\
\hline ALBRK & 0 & 0 & 0 & 0 & 0 & 0 & Privately owned bank \\
\hline GARAN & 1 & 1 & 1 & 0 & 1 & 0 & Foreign bank \\
\hline SAHOL & 0 & 0 & 0 & 0 & 0 & 0 & Privately owned bank \\
\hline HALKB & 1 & 1 & 1 & 1 & 0 & 0 & State-owned banks \\
\hline SKBNK & 1 & 1 & 1 & 1 & 0 & 1 & Privately owned bank \\
\hline ISCTR & 0 & 0 & 0 & 0 & 0 & 0 & Privately owned bank \\
\hline VAKBN & 0 & 0 & 0 & 0 & 1 & 0 & State-owned banks \\
\hline YKBNK & 0 & 0 & 0 & 1 & 1 & 1 & Privately owned bank \\
\hline TSKB & 0 & 0 & 0 & 1 & 0 & 0 & Privately owned bank \\
\hline DENIZ & 0 & 0 & 0 & 0 & 0 & 0 & Foreign bank \\
\hline Systemic risk & 0.273 & 0.273 & 0.273 & 0.364 & 0.273 & 0.182 & - \\
\hline
\end{tabular}


TABLE 4: Changes in assets value with Hurst index $\mathrm{H}$.

\begin{tabular}{lcccc}
\hline $\mathrm{H}$ & Change range of $\mathrm{H}(\%)$ & Asset value & Range of change in assets & Hurst index elasticity of asset value \\
\hline 0.34175222 & -50 & $3.62282 \mathrm{E}+11$ & -0.0038141 & 0.0076282 \\
0.45566962 & -30 & $3.62797 \mathrm{E}+11$ & -0.0023978 & 0.0079927 \\
0.51262832 & -10 & $3.62779 \mathrm{E}+11$ & -0.0024491 & 0.0244910 \\
0.56958703 & 0 & $3.63669 \mathrm{E}+11$ & 0 & - \\
0.62654573 & 10 & $3.637 \mathrm{E}+11$ & 0.0000852 & 0.0000852 \\
0.74046313 & 30 & $3.63707 \mathrm{E}+11$ & 0.0001045 & 0.0003483 \\
0.85438054 & 50 & $3.63746 \mathrm{E}+11$ & 0.0002117 & 0.0004235 \\
\hline
\end{tabular}

TABle 5: Abbreviations of banks of Turkey.

\begin{tabular}{lc}
\hline Bank abbreviation & Full name of bank \\
\hline AKBNK & Akbank TAS \\
ALBRK & Albaraka Turk Katilim Bankasi AS \\
GARAN & Turkiye Garanti Bankasi \\
SAHOL & Haci Omer Sabanci Holding AS \\
HALKB & Turkiye Halk Bankasi \\
SKBNK & Sekerbank TAS \\
ISCTR & Turkiye Is Bankasi AS \\
VAKBN & Turkiye Vakiflar Bankasi TAO \\
YKBNK & Yapi ve Kredi Bankasi AS \\
TSKB & Turkiye Sinai Kalkinma Bankasi AS \\
DENIZ & Denizbank AS \\
\hline
\end{tabular}

these five banks are all stable. At the same time, observing the assets of AKBNK Bank, SAHOL Bank, and ISCTR Bank, we can see that compared with other banks, they are big asset banks.

(2) From a theoretical point of view, Turkey has banks defaulting every year, which means that the banking system in Turkey is less stable and the economic situation is unstable, which is also in line with the actual situation in Turkey. Turkey's stimulus-driven growth in recent years has contributed to large economic imbalances that left the economy susceptible to shocks. As growth became increasingly dependent on external funds, credit, and demand stimulus, Turkey's economy began to exceed its potential, with a huge fiscal deficit and high inflation [1]. These imbalances make the Turkish economy vulnerable to changes in market sentiment and become more unstable.

(3) HALKB did not have basic default and contagion default in 2018 and beyond, which means that it has developed well and is not vulnerable to contagion from other banks, which is more stable than before. As Turkey's state-owned banks, VAKBN and HALKB are not vulnerable to the impact of the external environment and default during the Turkish financial crisis. Therefore, they believe that they have a strong antirisk ability, which also benefits from the capital injection and policy support of the Turkish government when the economic situation is unstable. However, in theory, other private banks, such as SKBNK and GARAN, are prone to default, which shows that they are extremely unstable and vulnerable to the impact of the external environment, which is opposite to the former.
3.2.4. Elasticity Analysis of the Hurst Index. The data in Table 4 clearly show that when the Hurst index increases, the Hurst index elasticity of assets value increases with the increase of the Hurst index, and the banks' assets value also increases. Hurst index elasticity refers to the ratio of changes in asset values to changes in the Hurst index. The change of the Hurst index has a positive impact on the assets value. That is, the higher the positive correlation between the past price and the future price of a stock, the greater the equity value of the bank. It is also consistent with our perceptual understanding: the clearer the direction of price change of stock, the smaller the risk of buying and selling stocks, the greater the chance of obtaining deterministic returns, and the higher the assets value of a bank. The conversion from classical B-S option pricing model with $H=0.5$ to fractional option pricing model with $H>0.5$ has a significant impact on assets value. Therefore, the measurement framework proposed in this paper based on fractional Brownian motion can better monitor the systemic risk of the Turkish banking system.

\section{Conclusions}

This paper proposed a framework of the systemic risk measurement based on fractional Brownian motion based on the market characteristics to study the systemic risk of the Turkish banking system. The framework includes the dynamic evolutionary estimation algorithm of banks' asset value, the estimation algorithm of the interbank network, and the dynamic liquidation algorithm of the interbank assets. Firstly, this paper tested the normality of the stock market of Turkish banks and analyzed their Hurst indices. The results showed that the Hurst indices of banks in the Turkish stock market are all greater than 0.5 , and there is a clear "spike and thick tail" phenomenon in their stock price trend. Therefore, this paper presented a dynamic asset value estimation method based on the fractional Brownian motion. Then the dynamic sequence of the asset value of listed banks was estimated. Secondly, this paper used the maximum entropy algorithm and matrix method to calculate the interbank network structure of the Turkish banking system. Finally, the dynamic asset clearing algorithm was combined to calculate the systemic risk.

This paper found that the systemic risk of the Turkish banking industry is relatively high and the banking system is unstable from 2016 to 2018, which could be related to the economic shock caused by Turkey's political turmoil, the continued depreciation of the lira. As an emerging market country mainly dependent on imports, Turkey has shown strong economic growth in the past 20 years. With the 
weakening of reform, however, productivity growth slowed, and Turkey's economic expansion is increasingly dependent on the credit and demand stimulation of external financing. In addition, Turkey is a country with high inflation and low interest rates. It often has huge fiscal deficits (mainly debt financing), which leads to investor loss of confidence, weak international net investment position, and serious currency mismatch, aggravating the internal and external imbalance. These imbalances led to a significant devaluation of the lira and the associated recession. In summary, Turkey, as an emerging market country mainly dependent on imports, has poor stability of the whole banking system and high systemic risk. Its economic environment is strongly affected by external shocks, especially when the systemic risk reached a high point between 2016 and 2018. However, after experiencing the impact of the financial crisis, with the stimulation and help of major government policies, the overall environmental situation has improved; the economy has resumed growth; and the lira has gradually rebounded. In addition, for specific banks, AKBNK, ALBRK, SAHOL, DENIZ, and ISCTR banks have low systemic risk in all periods, which indicates that these banks are in good operating condition, while other banks have high systemic risk, which indicates that their operating condition is poor. Therefore, in the process of preventing the systemic risk of the Turkish banking industry, we should pay attention to those banks with more serious systemic risks. For banks with high contribution to the systemic risk, their regulatory authorities should strengthen their supervision, strictly control their capital adequacy ratio and nonperforming loan ratio, and supervise their cautious lending. For example, banks with excessive debt should restrict their lending through credit guarantees.

In future work, if systemic risks of the Turkish banking system can be collected, the systemic risks dynamically evolved according to the model framework can be compared to verify the effectiveness of the framework. In addition, according to the proposed method of measuring the systemic risk, we can calculate the macroprudential capital of each bank in combination with the principles of four risk allocation mechanisms, namely component $\mathrm{VaR}$, incremental $\mathrm{VaR}$, Shapley value, and $\triangle \mathrm{CoVaR}$, which have been studied by Gauthier et al. [37], Liao et al. [38], and Fan Hong et al. [39, 40], to further carry out quantitative macroprudential supervision research on the Turkish banking network system (Table 5).

\section{Data Availability}

The data used to support the findings of this study are available from the corresponding author upon request.

\section{Conflicts of Interest}

The authors declare that there are no conflicts of interest.

\section{Acknowledgments}

The authors thank the National Natural Science Foundation of China (71971054) and the Shanghai Natural Science Foundation (19ZR1402100) for their support.

\section{References}

[1] https://www.imf.org/en/Publications/CR/Issues/2019/12/26/ Turkey-2019-Article-IV-Consultation-Press-Release-StaffReport-and-Statement-by-the- 48920.

[2] T. Adrian and M. K. Brunnermeier, "CoVaR," The American Economic Review, vol. 106, no. 7, 2016.

[3] X.-M. Bai and D. Shi, "Measures of systemic risk in China's financial system," International financial research, vol. 31, no. 6, pp. 75-85, 2014.

[4] V. V. Acharya, L. H. Pedersen, T. Philippon, and M. Richardson, "Measuring systemic risk," Review of Financial Studies, vol. 30, no. 1, 2017.

[5] M. Wu, "Empirical study on systemic risk measurement of listed banks in China," Journal of Dalian University of Technology, vol. 39, no. 2, pp. 24-31, 2018.

[6] X. Huang, H. Zhou, and H. Zhu, "A framework for assessing the systemic risk of major financial institutions," Journal of Banking and Finance, vol. 33, no. 11, 2009.

[7] N. Tarashev, C. Borio and K. Tsatsaronis, "The systemic importance of financial institutions," BIS Quarterly Review, pp. 75-87, 2009.

[8] F. Black and M. Scholes, "The pricing of options and corporate liabilities," Journal of Political Economy, vol. 81, no. 3, 1973.

[9] R. C. Merton, "Theory of rational option pricing," Bell Journal of Economics and Management Science, vol. 4, no. 1, 1973.

[10] A. Lehar, "Measuring systemic risk: a risk management approach," Journal of Banking and Finance, vol. 29, no. 10, 2005.

[11] J. Sun and W. Lai, "Risk analysis of Chinese listed commercial banks based on contingent equity balance sheet," Journal of Wuhan University (Natural Science Edition), vol. 62, no. 4, pp. 462-466, 2009.

[12] F. Allen and D. Gale, "Financial contagion," Journal of Political Economy, vol. 108, no. 1, pp. 1-33, 2000.

[13] L. Eisenberg and T. H. Noe, "Systemic risk in financial systems," Management Science, vol. 47, no. 2, 2001.

[14] C. Upper and A. Worms, "Estimating bilateral exposures in the German interbank market: is there a danger of contagion?" European Economic Review, vol. 48, no. 4, pp. 827-849, 2004.

[15] S. Wells, “"Financial interlinkages in the United Kingdom's interbank market and the risk of contagion," Bank of England," Quarterly Bulletin, vol. 44, no. 3, p. 331, 2004.

[16] H. Degryse and G. Nguyen, "Interbank exposures: an empirical examination of contagion risk in the Belgian banking system," International Journal of Banking Central, vol. 3, no. 2, pp. 123-171, 2007.

[17] I. Lelyveld and F. Liedorp, Interbank Contagion in the Dutch Banking Sector, University Library of Munich, Munich, Germany, 2005.

[18] X. Fan, F. Yi, and D. Wang, "Dynamic characteristics of systemic risk in Chinese banks and identification of systemically important banks- - based on the analysis of CCA and DAG," Financial research, vol. 56, no. 11, pp. 82-95, 2013.

[19] J. Ma, X. Fan, and Y. Cao, "Risk estimation and systematic analysis of bilateral contagion in China's interbank market," Economic Research, vol. 53, no. 1, pp. 68-78, 2007.

[20] X. Fan, D. Wang, and L. Liu, "Size, correlation and measurement of systemically important banks in China," Financial research, vol. 55, no. 11, pp. 16-30, 2012.

[21] B. Qin and Y. Sun, "Financial structure and financial risk contagion from the perspective of network," Systems engineering theory and practice economic research, vol. 34, no. 9, pp. 2202-2211, 2014. 
[22] S. Cong, Z. Tan, and Z. Wang, "A new approach to the measurement of systemic risk in banking industry," Chinese Management Science, vol. 24, no. 5, pp. 54-64, 2016.

[23] H. Fan, "Research on quantitative calculation method of systemic risk in dynamic banking network system," Journal of Physics, vol. 63, no. 3, pp. 38901-38902, 2014.

[24] H. Fan and X. Liu, "Research on the infectious risk of dynamic Bank of China network system," System science and Mathematics, vol. 38, no. 2, pp. 220-235, 2018.

[25] H. Fan, Y. Zheng, and M. Yang, "A study on the dynamic evolution of systemic risk in China's banking system," Systems Engineering, vol. 37, no. 1, pp. 101-110, 2019.

[26] F. Li, Research on Fractional Black Scholes Option Pricing Model and Enterprise Value Evaluation, Guangdong University of Foreign Studies, Guangzhou, China, 2018.

[27] P. Cheng, "Empirical study on option pricing of Shanghai stock Exchange 50ETF in fractional brownian motion environment," Economic Mathematics, vol. 36, no. 3, pp. 9-15, 2019.

[28] Y. Censor and S. A. Zenios, "Parallel optimization: theory, algorithms and applications," Computers and Mathematics with Applications, vol. 35, no. 9, p. 143, 1998.

[29] C. Necula, "Option pricing in a fractional brownian motion environment," Pure Mathematics, vol. 2, no. 1, pp. 63-68, 2002.

[30] Y. Hou, Pricing of New European Options in Fractional Brownian Motion, Probability Theory and Statistics of Northeast University, Boston, MA, USA, 2013.

[31] J. C. Duan, "On the equivalence of the KMV and maximum likelihood methods for structural credit risk models," Mathematical Finance, vol. 10, no. 4, pp. 155-167, 1994.

[32] J. C. Duan, "Correction: maximum likelihood estimation using price data of the derivative contract (mathematical finance 1994, 4/2, 155-167)," Mathematical Finance, vol. 10, no. 4,2000 .

[33] J. C. Duan, G. Gauthier, and J. G. Simonato, "On the equivalence of the kmv and maximum likelihood methods for structural credit risk models," Mathematical Finance, 2004.

[34] L. Zou, Application of Fractional Brownian Motion in Option Pricing, Quantitative Economics of Anhui University of Finance and Economics, Bengbu, China, 2015.

[35] I. Talasl,, "Systemic risk analysis of Turkish financial institutions with systemic expected Shortfall," Central Bank Review, vol. 13, no. 3, pp. 25-40, 2013.

[36] F. Yang, "Current status and trend of Turkish banking," Journal of Hangzhou Institute of Financial Research, vol. 35, no. 4, pp. 53-56, 2020.

[37] C. Gauthier, A. Lehar, and M. Souissi, "Macroprudential capital requirements and systemic risk," Journal of Financial Intermediation, vol. 21, no. 4, pp. 594-618, 2012.

[38] S. Liao, E. Sojli, and W. W. Tham, "Managing systemic risk in The Netherlands," International Review of Economics and Finance, vol. 40, pp. 231-245, 2015.

[39] H. Fan, C. Moses Keregero, and Q. Gao, "The application of macroprudential capital requirements in managing systemic risk," Complexity, vol. 2018, Article ID 4012163, 15 pages, 2018.

[40] Q. Gao and H. Fan, "Research on macroprudential supervision of China's banking system," Operations Research and Management, vol. 29, no. 3, pp. 158-168, 2020. 